\title{
ROBERTO MOREIRA, AULAS PARTICULARES E O ENSINO DE ARITMÉTICA NO SÉCULO XIX
}

\author{
Waléria de Jesus Barbosa Soares ${ }^{1}$
}

\section{RESUMO}

Apresentamos uma investigação sobre Roberto Antonio Moreira, maranhense, professor e autor de livros de matemática, que viveu na cidade de São Luís, no século XIX. Através de sua história de vida, objetivamos construir um texto biográfico, até onde os dados permitiram resgatar, além de tecer considerações sobre sua vida profissional envolvida pela publicação de suas obras. O presente texto, de metodologia qualitativa, constitui uma pesquisa de abordagem documental, que utiliza fontes primárias dos arquivos da Biblioteca Pública Benedito Leite, do Arquivo Público do Estado do Maranhão e do Liceu Maranhense. Estamos pautados teoricamente, em Bittencourt (2004), Ferrarotti (2010), Morais (2017), Paulilo (1999) e Valente (2008). Acreditamos que descortinar histórias de vida de autores de livros de matemática aproxima-nos do entendimento de como se construiu o ensino de matemática no local e tempo investigados - contribuindo, portanto, para compor um quadro do Brasil.

Palavras-chave: História de vida. História de vida profissional. Professor de matemática.

\section{ROBERTO MOREIRA, PARTICULAR CLASSES AND THE TEACHING OF ARITHMETICS IN THE 19TH CENTURY}

\section{ABSTRACT}

We present an investigation about Roberto Antonio Moreira, a maranhense, professor and author of mathematical books, who lived in the city of São Luís in the 19th century. Through his history of life we aim to construct a biographical text as far as the data allowed to rescue, besides weaving considerations about his professional life in the publication of his works. The present text, with a qualitative methodology, is a documentary approach, which uses primary sources from the archives of the Benedito Leite Public Library, the Public Archive of the State of Maranhão and the Liceu Maranhense. We are theoretically based on Bittencourt (2004), Ferrarotti (2010), Morais (2017), Paulilo (1999) and Valente (2008). We believe that uncovering life histories of authors of mathematics books brings us closer to the
\end{abstract}

1 Doutora em Ensino de Ciências e Matemática (UNICAMP). Professora de Matemática integrante do Nucléo de Currículo da Secretaria Municipal de Educação de São Luís (SEMED).E-mail:walleria_soares@hotmail.com 
understanding of how mathematics teaching was built at the place and time investigated - and this contributes to compose a picture of Brazilian studies.

Keywords: Life's history. History of professional life. Math's teacher.

\section{ROBERTO MOREIRA, CLASES PARTICULARES Y LA ENSEÑANZA DE ARITMÉTICA EN EL SIGLO XIX}

\section{RESUMEN}

Esta artículo presenta una investigación sobre Roberto Antonio Moreira, maranhense, profesor y autor de libros de matemáticas, que vivió en la ciudad de São Luís, en el siglo XIX. Através de su historia de vida buscamos construir un texto biográfico hasta donde los datos permitieron rescatar, además de tejer consideraciones sobre su vida profesional envuelta por la publicación de sus obras. El presente texto, de metodología cualitativa, constituye una investigación de abordaje documental, que utiliza fuentes primarias de los archivos de la Biblioteca Pública Benedito Leite, del Archivo Público del Estado de Maranhão y del Liceo Maranhense. En el caso de que se produzca un cambio en la calidad de la información. Consideramos que descortinar historias de vida de autores de libros de la matemáticas nos acerca al entendimiento de cómo se construyó la enseñanza de matemática en lo local y en el tiempo investigado - contribuyendo, por lo tanto, a componer un cuadro de su situación en Brasil.

Palabras clave: Historia de vida. Historia de la vida profesional. Profesor de matemáticas.

\section{INTRODUÇÃO}

Construir um texto biográfico nos possibilita tomar alguém como personagem. Nessa construção, podemos aprender com nossa biografia, mas também, podemos aprender com a biografia dos outros, daqueles que foram os antepassados profissionais, dos professores de matemática atuais (VALENTE, 2008).

Para a construção deste texto, apresentamos uma biografia que nos retrata a história de vida e de vida profissional de um autor de livros didáticos e professor de matemática, que viveu no Maranhão, especificamente em São Luís, no século XIX: Roberto Antonio Moreira.

A escolha por esse autor se deu pelo achado de uma de suas obras, ainda existente, na Biblioteca Pública Benedito Leite, localizada em São Luís. A obra, sem capa, apresentava na primeira página (que encontramos) o 
título: Tabella de Cambio - Página Íntima. Para compreender este título, e a obra por completo (que não é objetivo desta pesquisa neste momento), reconhecemos que, primeiramente, seria necessário conhecer seu autor, pois concordamos com Schubring (2003, p.17), sobre a existência de um "método histórico que se oferece para ampliar a compreensão de textos: a prosopografia, isto é, descobrir a respeito de características comuns das biografias dos autores em questão, seus precursores, etc".

Precisou-se, então, voltar ao Maranhão do século XIX e encontrarmos uma sociedade com problemas não muito diferentes daqueles que atingiam o resto do país. Observamos que, somente em meados do século XIX, quando o livro didático passou a ser o estruturador das disciplinas escolares, que sua produção realmente cresceu, as livrarias ampliaram suas funções e intensificou-se a função do professor como autor. Sobre esses autores, Bittencourt (2004, p. 481) lembra que "com maior ou menor autonomia, foram os criadores de textos didáticos que possibilitaram a configuração de uma produção nacional, com características próprias".

Para construir uma biografia sobre Moreira, seguimos pistas deixadas pelo tempo, pois acreditamos que ele "não passa sem deixar rastros, resíduos" (JOSÉ, 2012, p. 12). Vemos a biografia como um documento relevante, no que diz respeito ao conhecimento sobre a história de vida de uma pessoa, incluindo nomes, locais, fotos e datas dos principais acontecimentos. Sobre a importância da história de vida, concordamos com Paulilo (1999), para quem,

A história de vida pode ser, desta forma, considerada instrumento privilegiado para análise e interpretação, na medida em que incorpora experiências subjetivas mescladas a contextos sociais. Ela fornece, portanto, base consistente para o entendimento do componente histórico dos fenômenos individuais, assim como para a compreensão do componente individual dos fenômenos históricos (PAULILO, 1999, p. 142-143).

Portanto, a biografia contribui quando surge como uma possibilidade de revelar aspectos do fenômeno educativo até então não investigados. 
Mergulhamos nas fontes primárias dos arquivos maranhenses e envolvemo-nos em histórias contidas em textos, livros, notícias de jornais, documentos escolares, para então concordarmos com Ferrarotti (2010, p. 45), quando diz que "se todo o indivíduo é reapropriação singular do universal social e histórico que o rodeia, podemos conhecer o social a partir da especificidade irredutível de uma práxis individual".

Aceitar a subjetividade e a historicidade pulsantes, nessa gama de materiais, faz com que aceitemos que a história de uma sociedade pode estar contida na história de vida de cada autor ou docente, e aqui apresentamos a história de vida de um professor/autor de livro didático a ser utilizado em aulas de matemática no Maranhão do século XIX.

\section{UM POUCO SOBRE A SOCIEDADE LUDOVICENSE À ÉPOCA DE ROBERTO MOREIRA}

Roberto Moreira viveu em uma época em que o Maranhão alcançou momentos de picos no desenvolvimento econômico, devido à agricultura de produtos, como arroz, algodão, cana-de-açúcar e café.

A prosperidade foi refletida principalmente na capital, São Luís. A arquitetura da cidade ficou caracterizada pela construção de casarões revestidos de azulejos, semelhantes aos da Europa, que na maioria, serviam de casas para os grandes fazendeiros. São Luís também concentrava a riqueza comercial da cidade. Nela, se encontrava o maior centro comercial e cultural do Estado, conhecido como Praia Grande.

A educação foi impulsionada a partir da lei de 15 de outubro de 1827 , que determinava a criação de escolas primárias ou de primeiras letras em todas as cidades, vilas e lugarejos populosos.

Em 1838, foi inaugurado o Liceu Maranhense, segunda escola de ensino secundário no Brasil. O Liceu abrangia principalmente a elite, assim, em 1841, através da Lei Provincial No 105, de 23 de agosto de 1841, foi fundada a Casa dos Educandos Artífices, destinada aos meninos pobres.

Posteriormente, outros colégios foram sendo criados, como o Colégio Nossa Senhora da Glória (1844), destinado às meninas, mas que tinha um 
espaço também para meninos que pretendiam entrar para 0 Liceu Maranhense.

O desenvolvimento social e intelectual ficou mais evidente em meados do século XIX. O Teatro União (1841), posteriormente Teatro São Luiz (1852), e finalmente Teatro Arthur Azevedo (já no século XX), foi palco de grandes espetáculos vindos do exterior.

Os ludovicenses também acompanhavam o crescimento das livrarias e das tipografias. Jornais, livros, revistas e periódicos eram publicados na cidade e serviam como instigadores de pensamentos. São Luís se tornou o centro editorial das províncias e de importância nacional, pois a qualidade das impressões era consideravelmente melhor que a da própria cidade do Rio de Janeiro.

A literatura fez São Luís ficar conhecida no século XIX como Athenas Brasileira, devido ao grande número de literários que ali viveram, como Gonçalves Dias, João Lisboa, Cândido Mendes, Odorico Mendes, Sousândrade, Humberto de Campos, nomes bastante conhecidos por volta de 1880. Neste ano, Aluísio Azevedo publica o seu livro, "O Mulato".

Todos esses acontecimentos beneficiaram principalmente a elite ludovicense, pois cabe ressaltar, que foi também na segunda metade do século XIX, com o surgimento do império, e com ele, o abandono e descaso com a rica região maranhense, que ocorreu o empobrecimento de todo o Maranhão.

\section{ROBERTO MOREIRA: história de vida entrelaçada por seus trabalhos}

Roberto Antonio Moreira nasceu no Maranhão, mas não sabemos a data. Era casado com Guilhermina Augusta Guimarães Moreira e juntos tiveram quatro filhos: Maria da Glória Guimarães Moreira, Manoel Augusto Guimarães Moreira, Paulo Emílio Guimarães Moreira e Alzira Augusta Guimarães Moreira.

Sua vida pessoal esteve entrelaçada pelo seu trabalho como professor. Assim, no dia 07 de janeiro de 1874, abriu uma Aula de Comércio, em São Luís, para 22 alunos. Na aula inaugural, enfatizou que antes da 
sequidão dos algarismos, faria algumas considerações de harmonia com o seu programa de ensino.

Moreira iniciou a aula declamando poesias do escritor romântico e pedagogista português António Feliciano de Castilho (1800 - 1875), criador do Método Castilho de leitura, que consistia num método de ensino infantil da leitura, baseado na utilização de uma cartilha. Em seguida, Moreira anunciou que condenva a leitura de textos extensos pelos jovens, assim, como o gosto dos deles por versos, para ele, duvidosos. Assim, inicia sua lição de cálculo, sem antes deixar de mencionar do que trataria nas aulas seguintes, como:

[...] o amor do trabalho e da própria profissão; história do comércio, sua importância e influência entre os povos; predicados da profissão de caixeiro, seus direitos e deveres que lhe dá a lei; valor do dinheiro como representante da propriedade e do trabalho; economia do dinheiro e do tempo, e o seu bom emprego; fugir de dívidas, evitar a miséria e suas consequências funestas (DIÁRIO DO MARANHÃO, 10/01/1874, p.2).

É de 14 de março de 1874, um dos primeiros anúncios de que Moreira publicaria uma obra para o ensino das aulas de comércio.

FIGURA 1: Anúncio de futura publicação de Roberto Moreira Gula pratica e methodica de con. tabilidade.-Vai publicar o sr. Roberto Moreira uma obra neste sentido; c, a julgar pelo titulo e pelas materias de que trata, deve ser muito interessante e util.

Fonte: Diário do Maranhão, 14/03/1874, p.3.

Três dias depois, o anúncio de que a obra já esteva no prelo: 
FIGURA 2: Anúncio do livro "Guia Prática e Methodica de Contabilidade"

\title{
ESTÁ NO PRÉLO GUIA PRBTICA E METHOOLCA
}

IIE

\section{CONTABILIDADE}

\author{
10 ALCATCR DE TODOS.
}

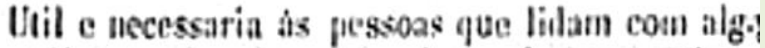

rismos, e carecen conlecer dias oficragrues arithmeticas mais geralmente usalias.

\section{RBDIGIIDO N COUSPILIIDO}

roth

\section{ROBER'TO A. MOREIRA}

Eimpregado no conmercio e profesior da sula it

contabilidade e escripturasgo mertantil, mat sociedate bendicente protectora dos

\section{CAIXEIROS.}

\section{EDTTORES $\mathrm{x}$ PROPRIETARIOS}

\section{A. PERERRA RAMOS DE ALMEIDA a C."}

Fonte: Diário do Maranhão, 17/03/1874, p.3.

De acordo com o anúncio acima, o livro compreendia os seguintes conteúdos:

A taboada, definições etc. As quatro especies em decimaes, reducção de quadrados á decimaes, e vice-versa para melhor compreensão e mais fácil aplicação do systema metrico, e para abreviar certas operações. O systema metrico decimal popular, e explicado, para os casos mais necessarios e triviais, com tabelas comparativas e exemplos que elucidam. Tabellas de fracções reduzidas á decimaes para simplificar calculos. Duas taboas dos dias do anno, para contas correntes, descontos etc. Methodo de tirar e conferir contas correntes com juros, pelos systemas mais simples e exactos. Tabellas de câmbios (de 22 a 28 pens por mil reis) com Inglaterra, Portugal e França: auxiliar importantíssimo. Notas diversas e uteis, como sejão: - Methodo de somar abreviado, sem nunca passar de desenove, seja qual for o numero de addicções. - Dito de simplificar certos calculos e faze-los mentalmente. - Theoria e 
pratica sobre proporções ou regra de três, para mais promta solução de muitos problemas de reducções, conversões, juros, etc., difíceis á primeira vista, porem que o conhecimento desta regra facilita muito. - Reducção de algumas moedas, medidas e pesos estrangeiros. - Idéas e regras á respeito das medidas cubica e quadrada. - Extractos da lei do sello - sobre sello fixo e proporcional em papeis comuns, etc.etc.etc. (DIÁRIO DO MARANHÃO, 17/03/1874, p.4).

No mesmo ano de 1874, Moreira anuncia outra obra publicada em São Luís: Tabela de Câmbio - Página Íntima.

FIGURA 3: Primeira páina do Tabella de Cambio-Página Íntima de Moreira
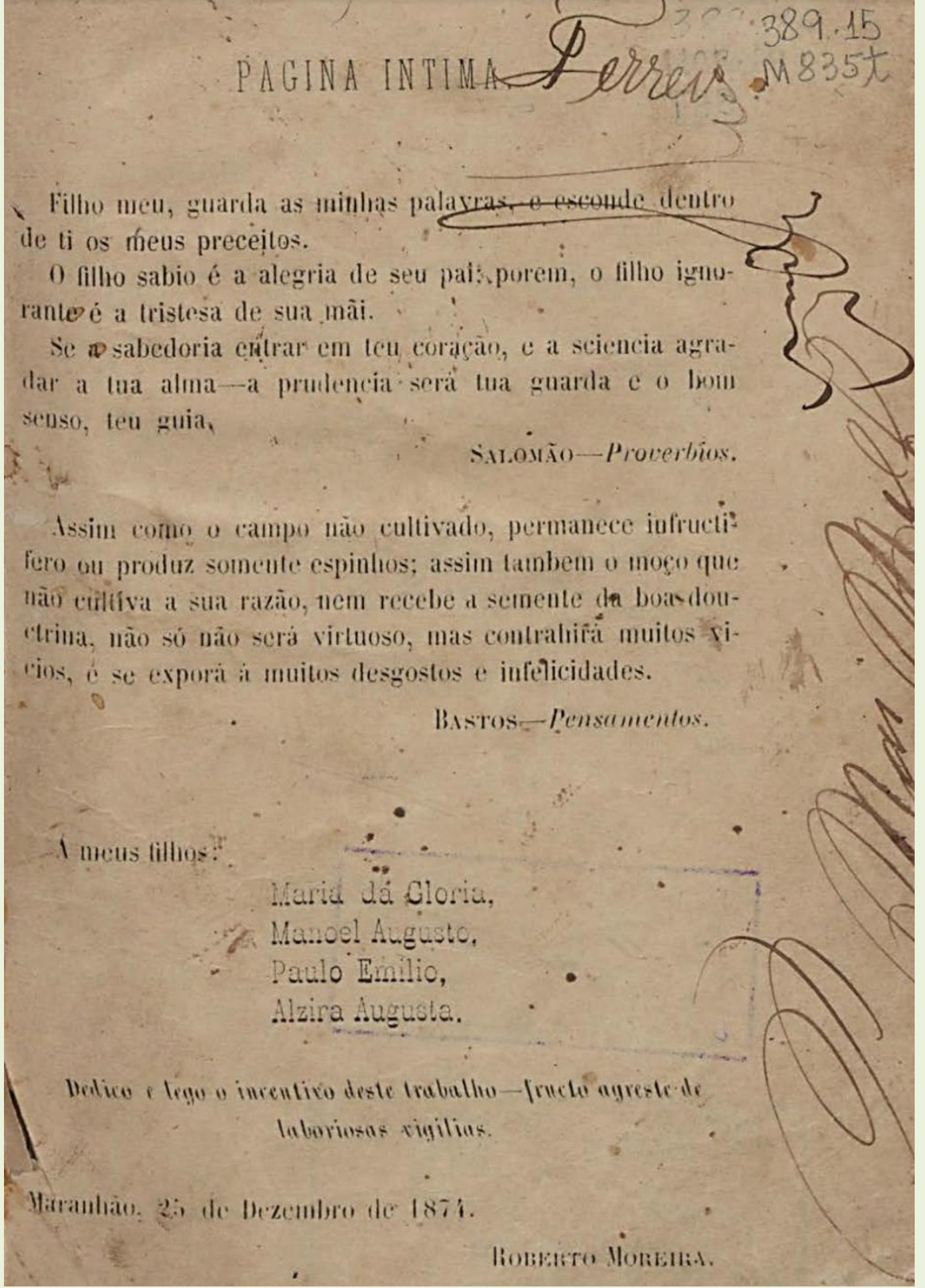

Fonte: Moreira, 1974, p.1.

Revista Exitus, Santarém/PA, Vol. 9, N², p. 161 - 185, ABR/JUN 2019. 
Segundo Soares (2018), este livro "se mostra totalmente diferente e inovador [...], sendo capaz de tratar de política, economia, religião, educação, profissionalização, dentre outros temas tão pertinentes de serem discutidos, e tudo isso num livro que trata de matemática".

Ainda em 1874, Moreira tem seu negócio em sociedade com o guarda civil, Frederico Augusto da Silva Guimarães, sob a firma de Roberto Moreira, Guimarães \& C., falido, e num leilão, os móveis do estabelecimento são vendidos. Também foram vendidos os escravos que para eles trabalhavam. Ressaltamos que, a falência foi declarada fraudulenta pelo juiz do comércio da época.

$\mathrm{Na}$ instrução, seus trabalhos envolviam o ensino de matemática e português. Assim, a partir de 1876, Moreira oferecia Aulas Noturnas de Contabilidade e Escrituração Mercantil, envolvendo problemas, exercícios e exemplos para quase todas as hipóteses matemáticas, através do método Sangey (que envolvia teoria e prática); ao mesmo tempo em que, a partir de 1877, oferecia Aulas Primárias (das 10h às 15h), envolvendo leitura, a boa pronúncia, significação das palavras, pontuação, etc. Nesse ano, seu endereço era a Rua do Sol, à direita, ao sair no largo do quartel, Centro de São Luís, onde o professor oferecia também aulas particulares.

Em 1879, divulga o regulamento do Collégio de São Sebastião (que veremos no tópico a seguir), do qual viria a ser dono e diretor. Também visa estabelecer na escola uma filial da Caixa Econômica. Esta ideia também seria acatada pelo professor de matemática João Miguel da Cruz, na Villa de São Bento, interior do Maranhão. Ambos os professores diziam que a intenção desta filial era levar lição de economia às escolas, mais do que qualquer intenção de lucros (O PAIZ, 24/05/1878, p. 2).

Moreira publica mais um livro em outubro de 1878, "Arithmetica do Povo", impresso por Magalhães e C. . A obra visava suprir a falta de um material que auxiliasse no ensino do cálculo, já que para Moreira faltavam obras com esse objetivo, pois os autores escreviam mais sobre a leitura e a escrita. 
Em 29 de janeiro de 1879, Moreira anuncia que, ao "Almanak do Diário do Maranhão" para o ano de 1879, iria junto a sua "Tabella de Câmbio", considerada pelo autor de grande utilidade para os assinantes e leitores. E, no mês de fevereiro, anuncia nos jornais o seu curso primário, assim também como suas Aulas Noturnas:

FIGURA 4: Anúncio de Aulas Noturnas por Moreira.

$$
\begin{aligned}
& \text { Aulas noctur- } \\
& \text { nas. }
\end{aligned}
$$

Segundss, q̨uartas o sextas.

Ferereiro de 1879. Ras do Sol.

Roberlo Moreira.

Fonte: Diário do Maranhão, 01/03/1879, p.3.

Moreira também tinha um lado poeta, sempre que possível, publicava suas poesias nos jornais. Algumas eram homenagens, como o tributo à 
memória do Dr Alexandre Theóphilo de Carvalho Leal, também professor de matemática, melhor amigo do poeta Gonçalves Dias:

\footnotetext{
Um dia, quando a história, na página brasílica,

Contar d'um feito ilustre o grau manancial,

Dirá - colhi o modo na plástica cortesia

D'um raro Ciacinato... d'um Theóphilo Leal.

Não fora destas éras que só discutem nomes,

E factos interesses de bastarda geração...

Vivera do passado, nas crenças puras, solidas;

Cabia-lhe o futuro na ardente aspiração

(JORNAL O PAIZ, 28/03/1879, p.2).
}

Ainda em 1879, a Sociedade Beneficente Protectora dos Caixeiros faz um contrato com Moreira para que ele lecione Português e Escrituração Mercantil aos sócios que se interessassem. Para este Curso Elementar de Conhecimentos Úteis, o professor Moreira ofereceu um programa que envolvia as seguintes aulas: ler, escrever e contar; Exercícios práticos teóricos de prosódia e ortografia; Escrituração mercantil e contabilidade; e, Gramática portuguesa.

Em 1880, suas aulas noturnas passam a acontecer na Rua do Egyto no prédio da Sociedade Onze de Agosto, Centro de São Luís. No final deste ano, Moreira muda novamente de endereço, agora Rua dos Afogados, $n^{\circ}$ 45, para onde leva também suas aulas noturnas e diurnas.

É também em 1880, que Moreira ganha espaço no Jornal Diário do Maranhão. Podemos citar dois artigos que escreveu, nos quais, o professor reflete sobre a educação. No artigo "O ensino escolar" (11/09/1880) tece comentários sobre a necessidade de reorganização dos conteúdos escolares, desde o ensino primário, como forma de erradicar, ou mesmo, amenizar a precária alfabetização das crianças. Em outro artigo, de 21 de setembro, ele condena o uso de castigos nos estabelecimentos escolares.

No Jornal O Paiz, sua presença não é diferente. Em 01 de junho de 1879, o artigo "A Refoma Ortografica, na coluna Sciencias, Lettras e Artes" traz à luz a discussão sobre o ensino de leitura e escrita; e o artigo "O Câmbio americano", (23/07/1879), ensina como calcular o dólar em moeda corrente. Ressaltamos que o resultado do cálculo apresentado por Moreira 
foi contestado no mesmo jornal dois dias depois (25/07/1979), assinado por "O curioso".

Em 1881 é anunciada a tiragem de "O Malho - chronica mensal". Neste jornal, Moreira é título do artigo: "O Sr. Roberto Moreira e o ensino de desenho".

Ainda em 1881, o Collégio de São Sebastião é finalmente criado.

Para o ensino de francês, Moreira também se aventura e publica um livro para o uso das aulas primárias.

FIGURA 5: Anúncio do livro Francez elementar $-1^{a}$ série de Moreira

\section{Flinlece elementar.}

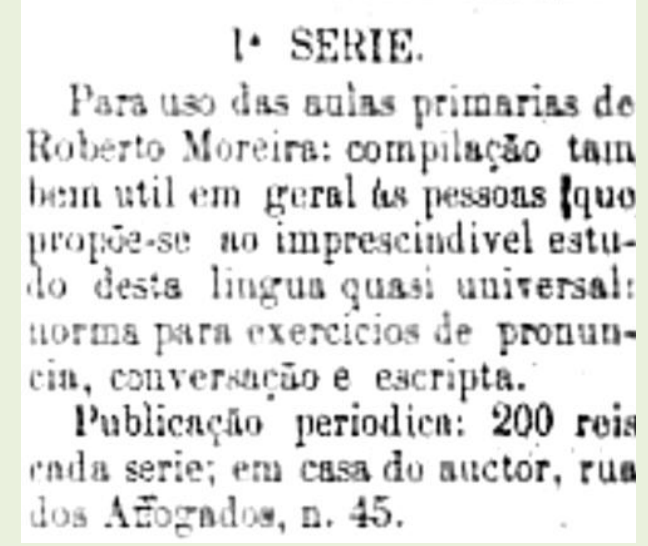

Fonte: Jornal Pacotilha, 16/04/1881, p.3.

Em 1883, Moreira continua a anunciar aulas noturnas em sua residência, que envolvem aulas primárias, quatro vezes por semana, e aulas de cálculo e escrituração mercantil, três vezes por semana. Neste mesmo ano, ao ser publicado o Almanack do Diário do Maranhão para 1883, temos mais uma vez as contribuições de Moreira, pois,

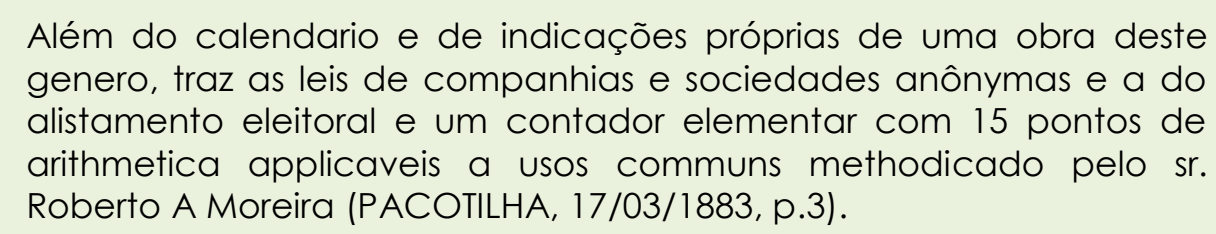

Quando em abril de 1883, ele viaja ao Pará, o Collegio São Sebastião fica sob a responsabilidade de sua esposa e do Sr. Carlos Rego, inclusive, para admitir novos alunos. Moreira foi trabalhar na Casa de Águas do Gram 
Pará, como guarda-livros, fazendo o balanço de contas gastas pela companhia.

Em 1885, publica mais um trabalho que auxiliaria nas aulas de comércio:

FIGURA 6: Anúncio de venda da "Taboa Synoptica de Cambio".

\section{Taboa synoptica de cam- bios entre a Inglater a e o Brazil e vice-versa \\ nas tasas de 18 a ga ofragües até 16 de Penay: \\ applicarel tambern aos cambius cota Portugal, Frsoça, Alletnabba o Estados-Unidos - por Roberto Morei. ra, à reada na}

\section{L.IVRARL BANOS D'ALMEI} D. \& C. ${ }^{2}$ 10

Fonte: Diário do Maranhão 08/05/1885, p.3.

No Ceará, em novembro de 1886, na sessão do Conselho da Instrução Pública de Fortaleza, foi anunciado o recebimento do "opúsculo denominado - Subsidio Industrial - de Roberto A. Moreira" (O LIBERTADOR, 25/11/1886, p.2).

Em 24 de dezembro, novamente no Pará, o próprio Moreira assina uma nota chamada "Gratidão" comentando a dor da perda da filha, Maria da Glória, em 1888.

O seu interesse pela matemática e pelas aulas de comércio acarretam a escrita de mais um livro. Em junho de 1892, já em São Luís, Moreira afirmava que sua obra que ainda viria a ser publicada denominada Memoradum Commercial - não se refere a umas tabelas de câmbio que estavam sendo distribuídas pela cidade e que seriam cópias fiéis de uma obra também chamada Memorandum - de autor desconhecido. 
De fato, o anúncio da venda de sua obra veio no mês seguinte: "Memoradum Commercial (de Roberto Moreira). A venda depois de 20 deste mez. Agentes. Julio Ramos \& C" (PACOTILHA, 06/07/1892, p.1).

Três dias depois do anúncio da venda de sua obra, Moreira se despede mais uma vez dos amigos em São Luís. Ele regressa novamente ao Pará e, assim, "faz votos ainda para que esta terra maranhense, sem desmentir as tradições de Athenas brasileira, saúda o novo século sobre os focos de Manchester da União, tal como os factos promettem" (PACOTILHA, 09/07/1892, p.2).

Em Belém, ele trabalhou como professor no Instituto Benjamim Constant. Em 31 de maio de 1899, chega novamente em São Luís, mas fica somente até 04 de agosto, retornando para Belém.

Roberto Antonio Moreira morreu em 1903, em Belém. Sobre sua morte, anunciou o jornal Pacotilha, de São Luís:

FIGURA 7: Anúncio da morte de Roberto Moreira

$\mathrm{Na}$ capital do visinho Estado do Pará, falleceu o maranhense Roberto Moroira, habiliszimo guarda-livros naquells praça.

O finodo deizon yoring trabalhos sobre escripturação mercantil, de cuja materia era lonte no lnst tuto Benjamin Constant, do Bolom.

Era um homem muito trabalhador $\theta$ honesto, sendo. por isso, geralmente estimado.

Apresentamos sentidos peza. mes a sua exma. familia.

Fonte: Pacotilha, 25/02/1903, p.1.

\section{DAS AULAS PARTICULARES DE MATEMÁTICA À CRIAÇÃO DE UMA ESCOLA}

Roberto Moreira sempre buscou desenvolver suas aptidões voltadas para o ensino. Desde 1874, passou trabalhar oferecendo aulas particulares como as de Comércio, de Contabilidade e Escrituração Mercantil. No final 
de 1877, oferecia aulas particulares em sua própria residência (Rua do Sol, $n^{\circ}$ 99. Centro de São Luís), que ficou conhecida ainda como Escola Particular de Roberto Moreira.

O ensino nestas aulas/escola visava ao interesse e à emulação dos alunos, e ainda, abolia o castigo corporal, de forma que buscava banir do aluno, qualquer medo que viesse a ter do professor, da escola e do próprio ensino. A emulação buscava despertar no aluno o sentimento que o fazia se igualar ou superar outrem. Mas deveria ser uma competição justa, com honestidade.

As categorias de ensino, como chamava Moreira, estavam divididas em Leitura, Cálculo, Ditado e Caligrafia. Sobre o cálculo, os exercícios abrangeriam "gradualmente as quatro espécies; fracções ordinárias e decimaes; systema-metrico-legal, proporções geométricas, etc." (DIÁRIO DO MARANHÃO, 11/06/1878, p. 1).

Os resultados obtidos após 10 meses de funcionamento da escola (que contava nesse momento com 35 alunos) foram apresentados por Moreira ao público em geral pelos jornais. A aritmética era sempre evidenciada em suas observações. Como, por exemplo, o que escreveu sobre a avaliação do aluno Manuel Augusto Guimarães Moreira (seu filho), de 7 anos, disse:

FIGURA 8: Avaliação do aluno Manuel Moreira

Faz desembarafyadaunente as contas te sommar, dimimuir' e multiplicar: jà couteçon a de repartir--de 2 a 9.

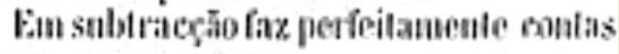
conn a jue segue:

MORI07(004398

$1015 \div 07200020$

Sa multiplicacoso, pode faret como a segutnte:

1ำ:400:4678?

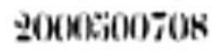

Da่ manแstripto: uas tem pouro gूosto para eservever.

Fonte: Diário do Maranhão, 26/10/1878, p.1. 
Sobre Maria da Glória Guimarães Moreira, também sua filha e aluna, ressalta que:

FIGURA 9: Avaliação da aluna Maria da Glória Guimarães Moreira

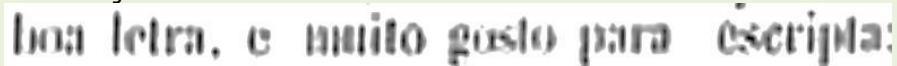
0 mesmo grau de alliantaneato en leiIur'a que sen irmão: fax lanuloen contas atc multiplicar-inferionnents: inpulle.

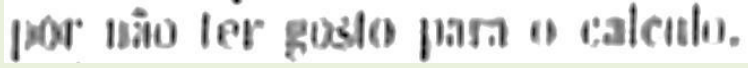

Fonte: Diário do Maranhão, 26/10/1878, p.1.

Quando Moreira diz que a aluna Maria da Glória não tinha a mesma aptidão para o cálculo que seu irmão, julgamos essa observação, a princípio, preconceituosa e sexista. O que não era de se estranhar na época.

Sobre os alunos Angelo Carlos Muniz e Joaquim José Muniz, de 12 e 10 anos respectivamente, o professor disse:

FIGURA 10: Avaliação dos alunos Angelo e Joaquim Muniz

Faz desembaragadamente as contas ile somuar, dimimuir e multiplicar: jả coluce. coan s de repartir-de 9 a 9.

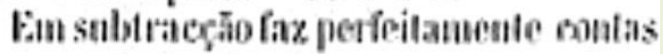
como a tue segne:

\section{RI07605398 \\ $1015 \div 07200020$}

Na multiplicaço, pode fazet cono a sogatnte:

18:300:4678!

$\pm 000 \% 00706$

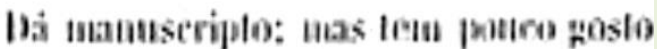
para esevever.

Fonte: Diário do Maranhão, 26/10/1878, p.1.

Sobre o aluno Carlos Alberto Catanho, de 10 anos de idade, a quem considerava extremamente acanhado, mas se admirava por responder cálculos de cabeça, Moreira disse que o menino: 
FIGURA 11: Avaliação do aluno Carlos Alberto Catanho

Foi os segunk la pouco en lirar o premio reputalo mais dislinclo da anla. Teu feito progressos mui notareis.

Ja está em quedrabos; li a escrere soffrivelmente e tem rara labilidate para calculos de cabera: do que se faz muilo exercicio nesta escoliti.

Por exemplo, ji responde, como ou. trus, com tal on inal farilitale a estas pergunlas:

Os tres setimos de iti:

Dous tercos de $2:$

68:30 क्या :

51:30 menos : : 20 :

30) carneiros a : 8.0000 :

inj ditilidas por 90 Iralkalhadores? pic.

Fonte: Diário do Maranhão, 26/10/1878, p.1.

Essa forma de expor os alunos nos jornais era, segundo o professor, uma forma de deixar o público em geral, a par de como ele procurava satisfazer o compromisso de instruir a mocidade local. Aos olhos de hoje, tal atitude chocaria os comitês de ética!

Em outubro de 1878, ao apresentar esses resultados, Moreira anunciava que no próximo mês iria transformar suas aulas num Curso Primário.

Os fins de seu curso não seriam "preparar estudantes para as carreiras scientificas ou litterarias; e sim, quando possível, educar e habilitar cidadãos para qualquer mister da vida" (DIÁRIO DO MARANHÃO, 26/10/1878, p.1). Nesse sentido, o professor afirmava que os alunos, ao fim de 10 ou 11 anos, saberiam ler, escrever e contar, sem esforço, e só após estarem aptos, passando por exames, é que passariam ao $2^{\circ} \mathrm{grau}$.

Seu programa de ensino seria composto de:

- $1^{\circ}$ grau: Ler, escrever e contar até as frações e sistema métrico legal, acompanhado de numerosos exercícios práticos, inclusive as lições das cousas; Doutrina cristã; Moral e civilidade; Noções de gramática nacional: tudo explicado nos próprios livros de leitura e de modo que o aproveitamento seja uma realidade. 
- $2^{\circ}$ grau: Desenvolvimento das matérias precedentes; Regras de proporções, e sua extensa aplicação às artes e indústrias; Escrituração mercantil; Higiene (conceitos e preceitos); Lições de geografia e história; Leitura explicada da Constituição do Império, etc; Gramática geral; Língua francesa: tendo por base o falar; Língua inglesa - do mesmo modo; Leituras públicas noturnas sobre assuntos recreativos (mas essa disciplina não era obrigatória).

O método continuaria a ser o simultâneo e o ensino visava ao interesse e à emulação, da mesma forma. O curso seria misto, e para as meninas, após terminarem $\circ 1^{\circ}$ grau, a família poderia optar para que elas continuassem no $2^{\circ}$ grau com o ensino elementar e profissional, ou pelo ensino industrial de trabalhos de agulha.

No ano seguinte, em 1879, ao seguir todo esse plano, o Curso Primário do professor Moreira deu início. Sobre os alunos, dizia que,

[...] dos doze aos quatorze annos um mocinho deve ou pode estar preparado - a fim de entrar para um lyceu, para uma casa de commercio, para uma officina, para uma repartição, etc. sabendo já alguma cousa immediatamente applicável em qualquer um desses tirocínios, a que se destine (DIÁRIO DO MARANHÃO, 10/04/1879, p. 1).

Em dezembro de 1879, Moreira anunciava que ampliaria seu Curso Primário, abrindo, portanto, um colégio. Ainda assim, no ano de 1880 continuou apenas com o curso e planejando a abertura da instituição. Ela veio acontecer apenas em 1881, e contava com familiares do professor como auxiliares, além de outros professores, e funcionava na Rua dos Afogados, n 45, Centro de São Luís, casa onde morava o professor.

Tratava-se do Collégio de São Sebastião, cuja direção ficou a cargo do professor Moreira e de sua esposa, Guilhermina Moreira. No seu funcionamento eram oferecidas, além do Curso Primário, aulas noturnas. O primeiro ocorria nas modalidades internato, semi-internato ou externato, ambos recebendo crianças, de ambos os sexos, até 12 anos de idade. As 
aulas diurnas aconteciam das $10 \mathrm{~h}$ às $14 \mathrm{~h}$ (ou 15h) e as aulas noturnas das $19 \mathrm{~h}$ às $21 \mathrm{~h}$.

O novo Curso Primário seria composto a princípio de nove matérias:

Leitura, escrita, contas, doutrina cristã elementar, moral e civilidade prática-explicada.

Ensino e exercício oral e escrito de prosódia e ortografia.

- Aritmética

- Gramatica nacional

- Língua francesa

- Desenho geométrico

- Cálculo e escrituração mercantil

- Língua inglesa

- Ideias gerais sobre ciências, artes e indústrias, por meio de definições e explicações - à vista das melhores enciclopédias.

Sua organização, segundo Moreira, estava de acordo com as necessidades locais e populares. Para as meninas, depois que tivessem desenvolvido certo conhecimento, a pretensão era que frequentassem cursos manuais, como o de agulhas, entre outros, da mesma forma como aconteciam nas aulas das escolas para meninas.

O professor Moreira, constantemente, anunciava nos jornais locais, qualquer novidade que acontecia na sua escola. Em maio de 1881, enfatizou as aulas manuais para meninas, assim como a mudança do colégio para outro endereço: 
FIGURA 12: Anúncio do Collégio de São Sebastião

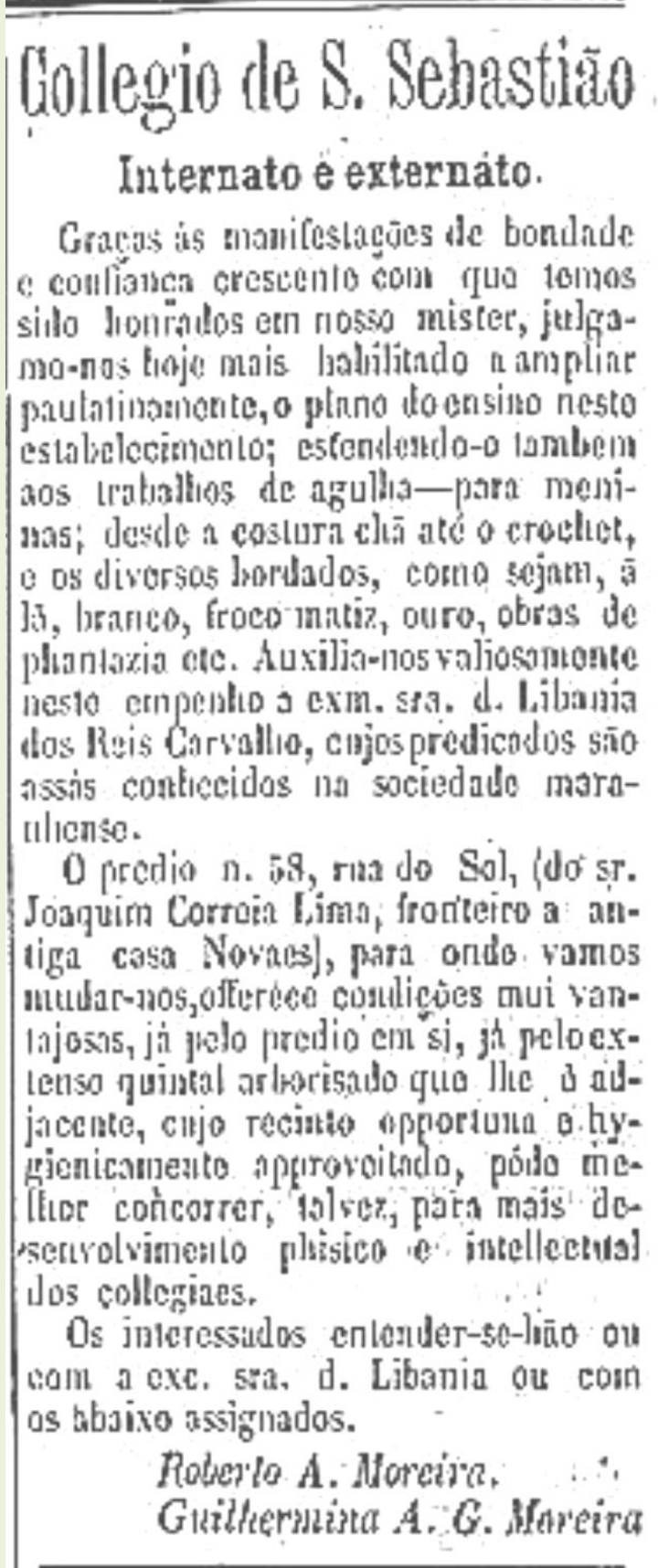

Fonte: Jornal Pacotilha, 02/05/1881, p.2.

Apesar do anúncio, eles se mudaram para Rua de São João, nº 33 Centro de São Luís (antiga Escola Pires).

Não só o colégio mudou de endereço, mas, Moreira se mudou com toda sua família, que incluía cunhadas e seus maridos, bem como os sobrinhos. Na residência antiga, continuou a funcionar outra escola primária, então dirigida pelo professor Antonio Pacífico da Cunha. 
FIGURA 13: Anúncio de mudança de endereço do Collégio de São Sebastião

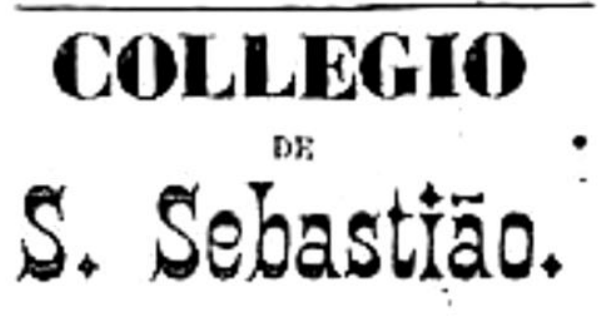
--Interaato e Externatio-

Roberto Moreira, con sua fomilia o seu modesto estabelecimento de educaçjo e instrucçio, trudoutse para a rua de S. Joso, tasa n... Jantiga escol Pires.]

Ahi, sobenellhores condiģōes de acechInodaçues e regimen escolur, suxiliado prot duas professoras e dous professo. res, espera continuar a merecer a confitaca dos srs. pais de familia. $\quad 8$

Fonte: Jornal Pacotilha, 10/12/1881, p.4.

Em dezembro de 1881, Moreira faz saber que precisava de uma pessoa para ajudá-lo na direção do colégio. Ele também deixa claro que o pretendido professor deveria ter conhecimento em gramática portuguesa, francês e aritmética, além de ter paciência, método e energia para lidar com as crianças.

Sobre o ensino de matemática, mais especificamente a aritmética que se lecionava no Collégio de São Sebastião, Moreira acreditava que quanto mais o ensino fosse simples e prático, mais proveitoso e menos enfadonho seria.

O método de ensino de Moreira, segundo ele, estava descrito na sua obra "Arithmetica do Povo", e consistia em começar dos exercícios mais simples para as hipóteses mais complexas. Dessa forma, Moreira acreditava que o aluno, mesmo sem ter conhecimentos prévios em tabuada, conseguiria resolver os problemas que envolviam as quatro operações. Ainda, para ele, seguir/utilizar o livro faria com que o professor ganhasse 
tempo em suas aulas, além de promover a emulação entre os alunos, o que consistia no melhor método de ensino.

Os resultados dos exames prestados pelos alunos ao Collégio de São Sebastião continuavam sendo anunciados nos jornais. E sempre que podia, Moreira enfatizava a aritmética:

Com o jornal de hoje publica o sr. Roberto Moreira um avulso com o resultado circunstanciado dos exames em seo collegio. É notável o numero de alumnos que apresentou a exames este anno e as materias a que respondem, especialmente em arithmetica (PACOTILHA, 23/12/1881, p. 2).

Não se sabe ao certo quando o colégio fechou suas portas, pois, a partir do ano de 1883, até a data de sua morte em 1903, Moreira, mesmo entre idas e vindas constantes em São Luís, foi trabalhar no Pará.

\section{CONSIDERAÇÕES FINAIS}

Na escrita deste trabalho seguimos Bloch (2001) e nos recolocamos, primeiramente, banhados pela atmosfera mental de um tempo, face a problemas que não pertenciam à sociedade maranhense de hoje, pelo menos, não na mesma conjectura, e tomando Ginzburg (2002, p.152) "a partir de dados aparentemente negligenciáveis, remont[ei] a uma realidade complexa não experimentável diretamente" que de alguma forma nos fez acreditar que "alguém passou por lá".

Buscamos assim, perceber Roberto Antonio Moreira constituído em seu tempo, a partir das relações com seus familiares, amigos e profissionais envolvidos em seu dia a dia.

Todo o contexto apresentado nos faz acreditar que Moreira foi um expert em seu tempo, pois foi reconhecido pela comunidade a que pertencia e pela sociedade em que viveu, sempre em relação à sua expertise profissional (MORAIS, 2017). Ele esteve envolvido com os intelectuais de sua época, principalmente, aqueles envolvidos com a matemática, como Alexandre Theóphilo de Carvalho Leal. 
Percebemos sua vontade e dedicação ao ensino, quando ele oferece aulas particulares em sua residência e toda a sua luta pela construção de uma escola.

Levar poesia às suas obras nos mostra como Moreira vê a literatura, como uma linguagem para expressar pensamentos, da mesma forma que a arithmética.

Conhecer a história de Moreira, parente profissional tão distante no tempo, mas não no espaço, leva-nos, enquanto professores de matemática, a acreditar que "seguimos o nosso caminho profissional na expectativa de melhor utilizar a herança que esses parentes nos deixaram profissionalmente, construindo novas práticas e saberes com esse legado" (VALENTE, 2008).

Reconhecemos que Moreira caminhou além dos livros didáticos de matemática. Sua produção trouxe para o Maranhão obras em outras áreas: francês, contabilidade, etc.

Acreditamos enfim que, descortinar histórias de vida de autores de livros de matemática aproxima-nos do entendimento de como se construiv o ensino de matemática no local e tempo investigados - contribuindo, portanto, para compor um quadro do Brasil.

\section{REFERÊNCIAS}

BITTENCOURT, C. M. F. Autores e editores de compêndios de livros de leitura (1810-1910). Educação e Pesquisa, 30(3), set./dez., p. 475-491, 2004.

BLOCH, M. Apologia da história: ou ofício de historiador. Rio de Janeiro: Jorge Zahar Editor, 2001.

FERRAROTTI, F. Sobre a autonomia do método biográfico. In: NÓVOA, A.; FINGER, M. (Org.). O método (auto)biográfico e a formação. Natal, RN: EDUFRN; São Paulo: Paulus, 2010.

GINZBURG, C. Sinais: raízes de um paradigma indiciário. In Mitos,

Emblemas e Sinais. 2. ed. São Paulo: Cia. das Letras, 2002.

JORNAL DIÁRIO DO MARANHÃO, 01/03/1879, p. 3.

JORNAL DIÁRIO DO MARANHÃO, 08/05/1885, p. 3. 
JORNAL DIÁRIO DO MARANHÃO, 10/01/1874, p. 2.

JORNAL DIÁRIO DO MARANHÃO, 10/04/1879, p. 1.

JORNAL DIÁRIO DO MARANHÃO, 11/06/1878, p. 1.

JORNAL DIÁRIO DO MARANHÃO, 14/03/1874, p. 3.

JORNAL DIÁRIO DO MARANHÃO, 17/03/1874, p. 3.

JORNAL DIÁRIO DO MARANHÃO, 17/03/1874, p. 4.

JORNAL DIÁRIO DO MARANHÃO, 26/10/1878, p. 1.

JORNAL DIÁRIO DO MARANHÃO, 26/10/1878, p. 1.

JORNAL O LIBERTADOR, 25/11/1886, p. 2.

JORNAL O PAIZ, 25/07/1979, p. 2.

JORNAL O PAIZ, 01/06/1879, p. 3.

JORNAL O PAIZ, 23/07/1879, p. 3.

JORNAL O PAIZ, 24/05/1878, p. 2.

JORNAL O PAIZ, 28/03/1879, p. 2.

JORNAL PACOTILHA, 02/05/1881, p. 2.

JORNAL PACOTILHA, 06/07/1892, p. 1.

JORNAL PACOTILHA, 09/07/1892, p. 2.

JORNAL PACOTILHA, 16/04/1881, p. 3.

JORNAL PACOTILHA, 17/03/1883, p. 3.

JORNAL PACOTILHA, 23/12/1881, p. 2.

JORNAL PACOTILHA, 25/02/1903, p. 1.

JOSÉ, E. Memória, cultura e literatura - O prazer de ler e recriar o mundo. São Paulo: Paulus Editora, 2012. 
MORAIS, R. S. Experts em educação e a produção de saberes no campo pedagógico. Revista de Matemática, Ensino e Cultura, Ano 12, n. 26, set-dez., p. 61-70, 2017.

MOREIRA, R. A. Página íntima. São Luís: [s.n.], 1874.

PAULILO, M. A. S. A Pesquisa Qualitativa e a história de vida. Serviço Social em Revista, Londrina, v. 2, n. 1, p. 1-153, jul./dez., 1999.

SCHUBRING, G. Análise histórica de livros de matemática: notas de aula. Campinas: Autores Associados, 2003.

SOARES, W. J. B. XIX - uma história, uma cidade e os primórdios da matemática escolar. Curitiba: Appris, 2018.

VALENTE, W. R. Quem somos nós, professores de matemática? Cadernos Cedes, Campinas, v. 28, n. 74, jan./abr., p. 11-23, 2008.

Recebido em: 28 de setembro de 2019. Aprovado em: 15 de janeiro de 2019. 